\title{
The Expression Levels of Notch-Related Signaling Molecules in Pulmonary Microvascular Endothelial Cells in Bleomycin-Induced Rat Pulmonary Fibrosis
}

\author{
Qian YIN ${ }^{1}$, Weihua WANG ${ }^{2}$, Guangbin CUI ${ }^{1}$, Haiyan NAN ${ }^{1}$, Linfeng YAN ${ }^{1}$, \\ Wenhu ZHANG ${ }^{3}$, Song ZHANG ${ }^{4}$, Jingguo WEI ${ }^{1}$ \\ ${ }^{1}$ Department of Radiology, Tangdu Hospital, Fourth Military Medical University, Xian, \\ P. R. China, ${ }^{2}$ Department of Pharmacy, Fourth Military Medical University, Xian, P. R. China, \\ ${ }^{3}$ School of Science, Engineering University of CAPF, Xian, P. R. China, ${ }^{4}$ Department of Pharmacy, \\ Tangdu Hospital, Fourth Military Medical University, Xian, P. R. China
}

Received March 24, 2016

Accepted October 3, 2016

On-line December 16, 2016

\section{Summary}

Previous studies have suggested that the Notch signaling pathway plays a very important role in the proliferation and differentiation of pulmonary microvascular endothelial cells (PMVECs). Therefore, we aimed to investigate the expression level of Notch-related signaling molecules in PMVECS in bleomycin (BLM)-induced rat pulmonary fibrosis. Immunohistochemistry, immunofluorescence, Western blotting, and real-time PCR were used to analyze the differences in protein and mRNA expression levels of Notch-related signaling molecules, i.e. Notch1, Jagged1, Delta-like ligand 4 (DII4), and hairy and enhancer of split homolog 1 (Hes1), between a control group treated with intratracheal instillation of saline and a study group treated with intratracheal instillation of BLM solution. Expression levels of the receptor Notch1 and one of its ligands, Jagged1, were upregulated, while the expression levels of the ligand DII4 and the target molecule of the Notch signaling pathway, Hes1, were downregulated. The differences in protein and mRNA expression levels between the control and study groups were significant $(p<0.001)$. The Jagged1/Notch1 signaling pathway is activated in the pathogenesis of BLM-induced rat pulmonary fibrosis, while the Dll4/Notch1 signaling pathway is inhibited, which inhibits the suppressive effect of DII4/Notch1 signaling on PMVEC overproliferation, further causing PMVEC dysfunction in cell sprouting and maturation as well as abnormal differentiation of the cell phenotype. Conversely, the downexpression of Hes1 indicates that the Jagged1/Notch1 signaling pathway could be a non-canonical Notch signaling pathway independent of Hes1 activation, which differs from the canonical DIl4/Notch1 signaling pathway.

\section{Key words}

Notch1 • Jagged1 • Dll4 • Bleomycin • Pulmonary fibrosis • Pulmonary microvascular endothelial cells

\section{Corresponding author}

Q. Yin, Department of Radiology, Tangdu Hospital, Fourth Military Medical University, Xian 710038, P. R. China E-mail: cissia@163.com

\section{Introduction}

Pulmonary fibrosis is the end pathologic stage of a series of diffused interstitial lung diseases that is characterized by different degrees of interstitial inflammation in the early stage and by the deposition of excessive collagen in the end stage. Pulmonary fibrosis usually results in respiratory failure and eventually death in the short-term, and the 5-year survival rate is less than $42 \%$ (Jegal et al. 2005). Recently, many experiments, including our animal model research, have shown that injury and abnormal proliferation of pulmonary microvascular endothelial cells (PMVECs) also play an important role in the early stages of progressive pulmonary fibrosis (Calabrese et al. 2005, Kasper et al. 2004, Takabatake et al. 2005). PMVECs, an important 
component of the air-blood barrier, are precursor cells against injury agents and are pivotal effector cell populations stabilizing homeostasis of the internal environment in the injury and remodeling process. It is believed that PMVECs not only participate in the inflammatory response, but also secrete several cytokines, such as endothelin-1 (ET-1), transforming growth factor- $\beta 1$ (TGF- $\beta 1$ ), and connective tissue growth factor (CTGF), to protect lung tissue from severe injury and to improve the remodeling of injured lung tissue in the general inflammatory process (Kuruvilla and Kartha 2009, Mauro et al. 2001, Muehlich et al. 2007, Mutsaers et al. 1998, Phan et al. 1991, Sakao et al. 2006). However, PMVECs proliferate at a higher rate in the early pathological process of bleomycin (BLM)-induced pulmonary fibrosis, and there is dysfunction in differentiation and maturation, with PMVEC transdifferentiation, such as endothelial-mesenchymal transition (Endo-MT). These major changes in PMVECs lead to increased microvascular permeability (Yin et al. 2012), worsened hypoxia, and profibrotic cell and cytokine infiltration, which finally cause the dramatic changes in the internal environment and facilitate the progress of pulmonary fibrosis. The above developments indicate that abnormalities in PMVEC proliferation and differentiation play an indispensable role in the pathogenesis of BLM-induced pulmonary fibrosis.

It is well known that the Notch signaling pathway between adjacent cells is an evolutionarily conserved pathway that regulates cell fate, including such events as differentiation, proliferation, and apoptosis (Clement et al. 2007, Kwon et al. 2012). When Notch receptors bind to Notch ligands (Jagged or Delta) expressed on adjacent cells, proteolytic cleavage involving secretase releases the intracellular domain of Notch (NICD), which then translocates into the nucleus, where it binds to its downstream transcription factor CSL (the mammalian homolog of $\mathrm{Su}[\mathrm{H}]$, also known as $\mathrm{CBF} 1$ or RBP-JK). This results in CSL being converted from a repressor to an activator, consequently inducing the transcription of Notch-dependent target genes such as HES1 (hairy enhancer of split 1), HRT (hairy-related transcription), $\mathrm{pT}$, meltrin, and the Notch receptors themselves. As confirmed in mammals, two of the four Notch receptors (Notch1 and Notch4) and three of the five Notch ligands (Jagged1, Delta-like ligand 1 [DLL1], and DLL4) are predominantly expressed in vascular endothelial cells (ECs) and are important for many aspects of vascular biology (Al Haj Zen and Madeddu
2009, Claxton and Fruttiger 2004, Kume 2012). The Dl14/Notch1 signaling pathway could be related with the inhibition of cell overproliferation and the stabilization of homeostasis, while the Jagged1/Notch1 signaling pathway is believed to promote EC proliferation and transdifferentiation (Aranguren et al. 2007) and plays a critical role in fibrotic diseases (Jurynczyk et al. 2005, Liu et al. 2009, Tu et al. 2005). We speculate that PMVECs undergo these events in BLM-induced pulmonary fibrosis and that overproliferation and transdifferentiation are closely related with imbalance between the Dll4/Notch1 and Jagged1/Notch1 signaling pathways. Therefore, in this study, we investigated the expression levels of the Notch1 pathway-related signaling molecules, namely Notch1, D114, Jagged1, and their downstream target molecule, the transcription factor Hes1. We believe that clear elucidation of the Notch1 signaling pathway alterations in BLM-induced pulmonary fibrosis would be helpful for disclosing the critical pathological turning point that promotes PMVEC overproliferation and abnormal transdifferentiation and help find the target molecule for preventing the progress of pulmonary fibrosis without interrupting the normal remodeling of injured lung tissue.

\section{Materials and Methods}

\section{Animals and experimental groups}

All experiments were performed in accordance with the guidelines of the Committee for Animal Research of the Fourth Military Medical University, Xi'an, P. R. China. Thirty-six male Sprague Dawley rats aged 3-4 weeks and weighing 80-100 g were obtained from the Animal Center of the Fourth Military Medical University. All rats were randomized into two treatment groups: BLM $(n=18)$ and control $(n=18)$. To induce pulmonary fibrosis, rats were anesthetized with an intraperitoneal injection of $10 \mathrm{~g} / 1$ sodium pentobarbital $(40 \mathrm{mg} / \mathrm{kg}$; Sigma-Aldrich, USA), followed by an intratracheal injection with $0.125 \mathrm{ml}$ BLM solution ( $15 \mathrm{mg}, 4 \mathrm{~g} / 1$ in sterile water; Nippon Kayaku Co Ltd., Japan) (Mutsaers et al. 1998). Control animals were injected intratracheally with $0.125 \mathrm{ml}$ sterile saline. The first day of instillation with the diseaseinducing BLM or saline control was designated day 1. Rats were euthanized at 7 days post-instillation. All rats from both treatment groups were sacrificed for primary cell culture and further experiments. To compare disease models and disease tissue, all experimental groups were evaluated by histochemical techniques, i.e. Harris's 
hematoxylin and eosin (H\&E) and Van Gieson (VG) staining, to visualize the degree of inflammation and fibrosis (Lang et al. 2008).

\section{Primary culture of PMVECS}

Rats were anesthetized with an overdose of sodium pentobarbital via intraperitoneal injection, and sternotomy was performed. The left auricle was exposed, and the right ventricle was perfused with $20 \mathrm{ml}$ phosphate-buffered saline (PBS) to flush blood from the lung vasculature. The lungs were then excised, the pleura were dissected, and a 1-2-mm edge of the lung tissue was cut into $1-\mathrm{mm}^{3}$ pieces. These fresh tissue pieces were dispersed and cultured in $25-\mathrm{ml}$ uncoated culture flasks with $3 \mathrm{ml}$ Dulbecco's modified Eagle's medium (DMEM; HyClone, USA) containing $20 \%$ fetal calf serum (FCS; HyClone) for $48-52 \mathrm{~h}$ at $37^{\circ} \mathrm{C}$ in the presence of $5 \% \mathrm{CO}_{2}$ until short spindle cells were seen migrating from the explants. The tissue explants were then removed from the culture flasks, and the cells were again cultured with $3 \mathrm{ml}$ DMEM containing $20 \%$ FCS until confluent cobblestone-like monolayers were formed. Then, the cells were fixed for immunofluorescence or harvested for further detection. The PMVECs used in this study were all from the primary passage.

\section{Immunohistochemistry}

The expression of proteins in rat lung tissue sections were directly evaluated by immunohistochemistry. Briefly, after 1-2 mm edges of the lung tissues were resected for cell culture, the rest of the lung tissue was fixed with $4 \%$ paraformaldehyde overnight at $4{ }^{\circ} \mathrm{C}$. The tissues were embedded in paraffin and subsequently sectioned into $4-\mu \mathrm{m}$ slices. Then, slides were dewaxed in xylene, rehydrated through decreasing concentrations of ethanol, and washed in PBS. Endogenous tissue peroxidase activity was blocked by incubating sections in $3 \%$ hydrogen peroxide for $3 \mathrm{~min}$. Afterward, sections were washed $3 \times 5 \mathrm{~min}$ in PBS, then incubated in $5 \%$ normal goat serum (BioGenex, USA) for $30 \mathrm{~min}$. The goat serum was drained and the tissue was blot-dried. Sections were incubated with specific antibody separately (rabbit polyclonal Notch1 antibody, 1:50; Proteintech, USA, and goat polyclonal Jagged1 [C-20] antibody, 1:100; goat polyclonal Dl14 antibody, 1:100; rabbit polyclonal Hes1 antibody, 1:100; Santa Cruz Biotechnology, USA) overnight at $4{ }^{\circ} \mathrm{C}$. After $3 \times 5$ min washes in PBS, sections were incubated with specific secondary antibody separately (goat anti-rabbit immunoglobulin $\mathrm{G}[\mathrm{IgG}]$ and rabbit anti- goat IgG, 1:500; Boster, China) for $30 \mathrm{~min}$ at $37^{\circ} \mathrm{C}$, washed $3 \times 5 \mathrm{~min}$ in PBS, and incubated with a streptavidin-peroxidase complex (working dilution, 1:100; DAKO, Denmark) for an additional $60 \mathrm{~min}$ at $37^{\circ} \mathrm{C}$. Specific protein immunolabeling was visualized after incubating sections in a solution of $600 \mu \mathrm{g} / \mathrm{ml}$ 3,3'-diaminobenzidine (DAB; Sigma-Aldrich) and $0.03 \%$ hydrogen peroxide for $3 \mathrm{~min}$. Sections were washed in water, counterstained with hematoxylin, dehydrated, and mounted with $50 \%$ glycerin mounting solution. For the negative control, sections were incubated with mouse IgG1 instead of primary antisera overnight at $4{ }^{\circ} \mathrm{C}$.

\section{Quantitation of specific protein immunostaining}

To semi-quantify protein expression in the lung sections, the mean grey value was assessed using ImageJ software (National Institutes of Health, NIH, USA). Six fields per section were examined in three randomly chosen sections per group.

\section{Immunofluorescence for cultured PMVECS}

Immunofluorescence staining was performed to examine Notch1, Jagged1, and Dll4 protein expression in the PMVEC monolayers. The fixed monolayer PMVECs were washed in PBS and incubated in $5 \%$ normal goat serum for $30 \mathrm{~min}$ at room temperature. The serum was then drained off and the slides were blot-dried. Monolayer PMVECs were incubated in specific antibody separately (rabbit polyclonal Notch1 antibody, 1:50; Proteintech, and goat polyclonal Jagged1 [C-20] antibody, 1:100; goat polyclonal Dl14 antibody, 1:100; all Santa Cruz Biotechnology) overnight at $4{ }^{\circ} \mathrm{C}$. After $3 \times 5$ min washes in PBS, they were incubated in specific second antibody (goat anti-rabbit IgG-fluorescein isothiocyanate and rabbit anti-goat IgG-tetramethylrhodamine isothiocyanate, 1:100; Boster) for $30 \mathrm{~min}$ at $37^{\circ} \mathrm{C}$. At the end of the staining, the slides were washed and incubated with 2-(4-amidinophenyl)-6indolecarbamidine dihydrochloride (DAPI, working dilution, 1:500; Sigma-Aldrich) for $5 \mathrm{~min}$ at room temperature and mounted with $50 \%$ glycerin mounting solution. Control slides were incubated with normal mouse IgG1 instead of primary antisera overnight at $4{ }^{\circ} \mathrm{C}$.

\section{Quantitation of specific protein immunostaining}

Semi-quantitative analysis of protein expression in the immunofluorescence cell slides was performed using ImageJ software (NIH), and the mean value of fluorescence intensity was assessed. All parameters, 
including lamp intensity, video camera setup, and microscope calibration, were held constant. Six fields per section were examined in three randomly chosen sections per group.

\section{Western blot analysis}

Western blotting was performed to detect Notch1, Jagged1, Dll4, and Hes1 protein expression in PMVECs. The culture medium was carefully removed from PMVECs. Cells were washed twice with cold PBS before the addition of cold RIPA Buffer (RIPA Lysis and Extraction Buffer, Thermo Fisher, USA). Then, $80 \mu \mathrm{l}$ of buffer was added to each $10 \mathrm{~cm}$ dish and kept on ice for 5 min with occasionally swirling. The lysate was gathered to one side using a cell scraper, collected and transferred to a microcentrifuge tube. Samples were centrifuged at $14,000 \mathrm{rpm}$ for $15 \mathrm{~min}$ to pellet the cell debris, and supernatant was then transferred to a new tube. A Bradford Kit (Biorad, USA) was used to measure the protein concentration of each sample. PMVECs lysates (adjusted to a final concentration $25 \mu \mathrm{g} / 10 \mu \mathrm{l}$ ) were separated using SDS-polyacrylamide gel-electrophoresis and transferred to nitrocellulose membranes (100 V, $1 \mathrm{~h})$. After blocking with PBS/0.1\% Tween 20 (PBS-T) containing $5 \%$ non-fat milk for $1 \mathrm{~h}$, the nitrocellulose blots were reacted separately with different antibodies
(Notch1 rabbit polyclonal antibody, 1:500; Proteintech, and Jagged1 [C-20] goat polyclonal antibody, 1:1000; Dll4 goat polyclonal antibody, 1:1000; Hes1 rabbit polyclonal antibody, 1:1000; Santa Cruz Biotechnology) in PBS-T with $5 \%$ bovine serum albumin overnight at $4{ }^{\circ} \mathrm{C}$. The filters were then washed $3 \times 10 \mathrm{~min}$ in PBS-T, incubated with horseradish peroxidase (HRP)-conjugated goat anti-rabbit IgG or HRP-conjugated rabbit anti-goat IgG (1:500 dilution in PBS-T with $5 \%$ non-fat milk; Boster) for $30 \mathrm{~min}$ at $37^{\circ} \mathrm{C}$, and washed $3 \times 10 \mathrm{~min}$ in PBS-T. Finally, immunoreactive proteins were detected with an enhanced chemiluminescence detection kit (Anmei, China) and exposed to XAR-5 film (Eastman Kodak, USA). $\beta$-actin (AbD Serotec, UK)-specific antibody was used as the internal control. The relative intensities of the protein bands were quantified by scanning densitometry (Quantity One; Bio-Rad, USA). Data are expressed relative to that of $\beta$-actin.

\section{$m R N A$ analysis by real-time PCR}

For mRNA analysis, total RNA was isolated from primary cultured PMVECs using TRIzol (Invitrogen, USA) and treated with DNase I (Ambion, USA). Total RNA (1 mg) was reverse-transcribed using SuperScript III First-Strand Synthesis SuperMix (Invitrogen). The primer sequences are presented in Table 1.

Table 1. Primer sequences designed using Primer Express 3.0 software.

\begin{tabular}{ll}
\hline Gene & Primer sequence 5'-3' \\
\hline Notch1 Forward & CGTGCTATGTTGTGGACCATGGC \\
Notch1 Reverse & CACACTCGTGGGTGGTGTCCCCCG \\
Jagged 1 Forward & ATGCGGTCCCCACGGACGCGC \\
Jagged 1 Reverse & GCCTTTCAATTATGCTATCAGG \\
Dll4 Forward & GCTGGAAGTGGATTGTGG \\
Dll4 Reverse & CTTGTCGCTGTGAGGATAC \\
Hes 1 Forward & GTCATCAAAGCCTATCATGGAG \\
Hes1 Reverse & GTGCGCCTGCCCGGGGTAGGTC \\
Rat- $\beta$-actin-138 Upper & AGATCCTGACCGAGCGTGGC \\
Rat- $\beta$-actin-138 Lower & CCAGGGAGGAAGAGGATGCG \\
\hline
\end{tabular}

Real-time PCR was performed in triplicate using SYBR Green Mix (Applied Biosystems, USA) and a 7500 Fast Real-Time PCR System (Applied Biosystems) under the following conditions: $15 \mathrm{~min}$ at $95^{\circ} \mathrm{C}$, followed by 40 cycles of $95^{\circ} \mathrm{C}$ for $15 \mathrm{~s}$ and $60{ }^{\circ} \mathrm{C}$ for $1 \mathrm{~min}$. Quantitative reverse transcription-PCR
(qRT-PCR) and data analysis were performed as described previously. Results are expressed as the comparative threshold value $\left(2^{-\Delta \Delta C T}\right)$.

\section{Statistical analysis}

Statistical significance was determined with 
an unpaired t-test. All data are shown as means \pm standard deviation (SD). A $p$-value of $<0.05$ was considered significant.

\section{Results}

\section{Animal models}

In the BLM rats, HE and VG staining revealed interstitial inflammation in the lung tissue and slight thickening of the alveolar septa with minor collagen deposition in the early stage of BLM-induced pulmonary fibrosis. In the control group, the alveolar septa were well-distributed, and only a small quantity of elastic fibers deposition was observed. This histological assessment demonstrated the successful establishment of pathology in the animal model (Fig. 1).
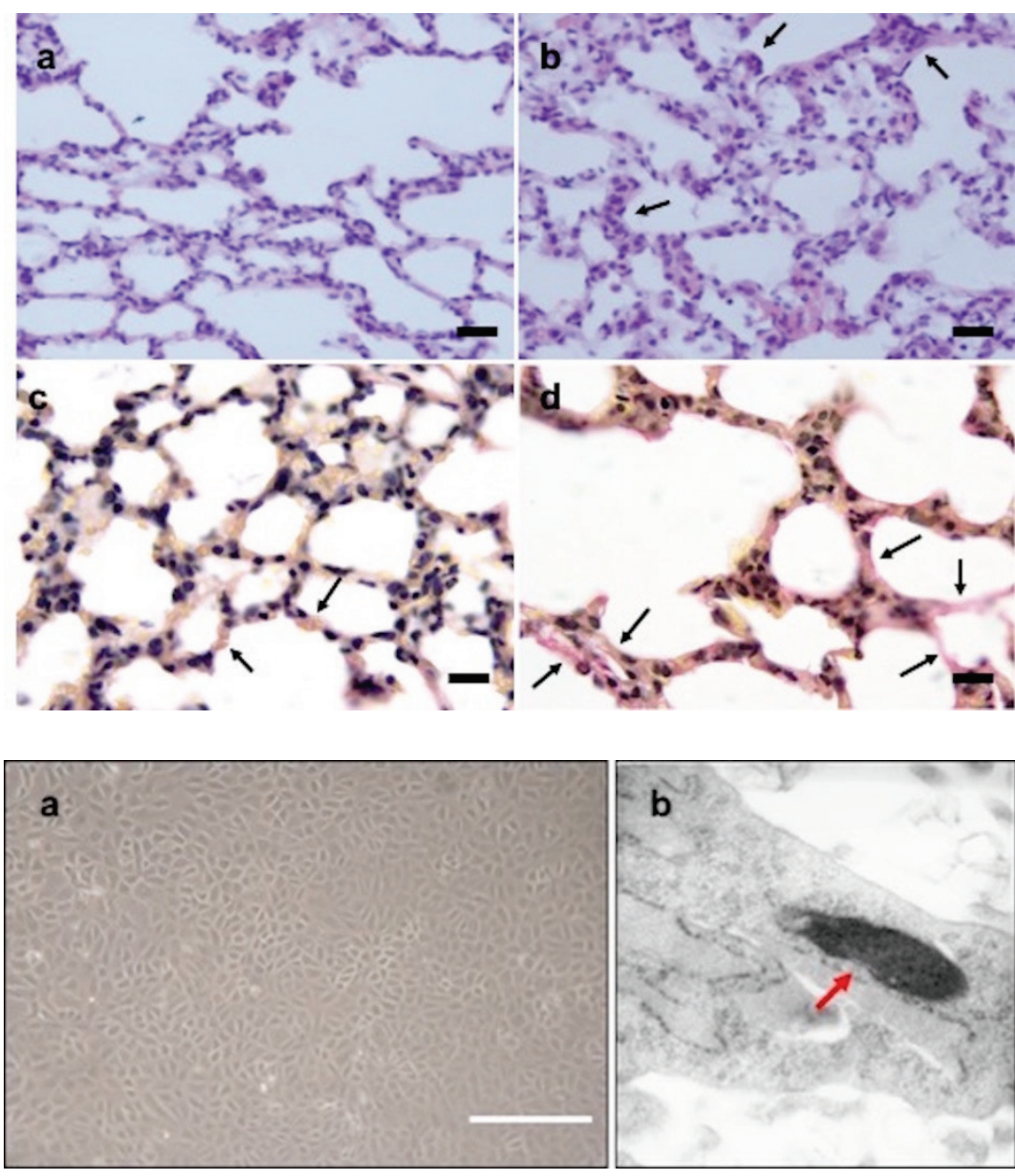

Fig. 1. Histopathological evaluation of lung tissue from experimental rats. (a) No obvious pathological changes in the control group (H\&E staining). (b) On day 7 in the BLM group, portions of the lung interstitium were thickened and there appeared to be more infiltrating inflammatory cells (arrows) (H\&E staining). (c) The alveolar septa were well-distributed and there were few elastic fibers and collagen deposits (arrows) in the control group (VG staining). (d) On day 7 in the BLM group, the alveolar septa were thickened, and there was a large quantity of collagen deposition (arrows) (VG staining). Scale bar for Figs $1 \mathrm{a}$ and $1 \mathrm{~b}=50 \mu \mathrm{m}$. Scale bar for Figs $1 \mathrm{c}$ and $1 \mathrm{~d}=20 \mu \mathrm{m}$. Images are representative of three different experimental animals per subgroup.

Fig. 2. Isolation and verification of PMVEC culture purity. (a) Confluent cobblestone-like monolayers of PMVECs. Scale bar $=200 \mu \mathrm{m}$. (b) W-P bodies in primary cultured PMVECs (arrow). (Magnified 60,000 times.)

\section{Primary culture and identification of PMVECs}

The PMVECs formed a cobblestone-like monolayer covering $60 \%$ of the glass coverslips within 3-4 days (Fig. 2a). Weibel-Palade bodies (W-P bodies) were observed in the cytoplasm of PMVECs by electron microscope (Fig. 2b).

Histochemistry analysis of Notch1, Jagged1, Dll4, and Hes 1 expression in lung tissue

As the immunohistochemistry staining and mean grey value assessment showed, there was significantly stronger expression of Notch1 protein in the lung tissues from BLM-treated rats as compared to that from the saline-treated rats (mean grey value: $189.76 \pm 6.30$ [BLM] vs. $167.86 \pm 9.09$ [control], $p=0.001$ ) (Fig. 3i). The expression of Jagged1 protein in lung tissues from the BLM group was also significantly stronger than that from the control group $(183.73 \pm 8.16$ [BLM] vs. $164.96 \pm 8.12$ [control], $p=0.003$ ) (Fig. 3i). Dll4 and Hes1 protein expression in BLM rat lung sections were slightly lower than that in the control group, but the differences were not significant $(p=0.479$ for Dll4 protein expression, $p=0.385$ for Hes1 protein expression), which was inconsistent with the cell immunofluorescence and Western blotting findings. This may have been because immunohistochemistry staining reflects the staining of multiple cell types in lung tissue sections, and not only that for PMVECs. 


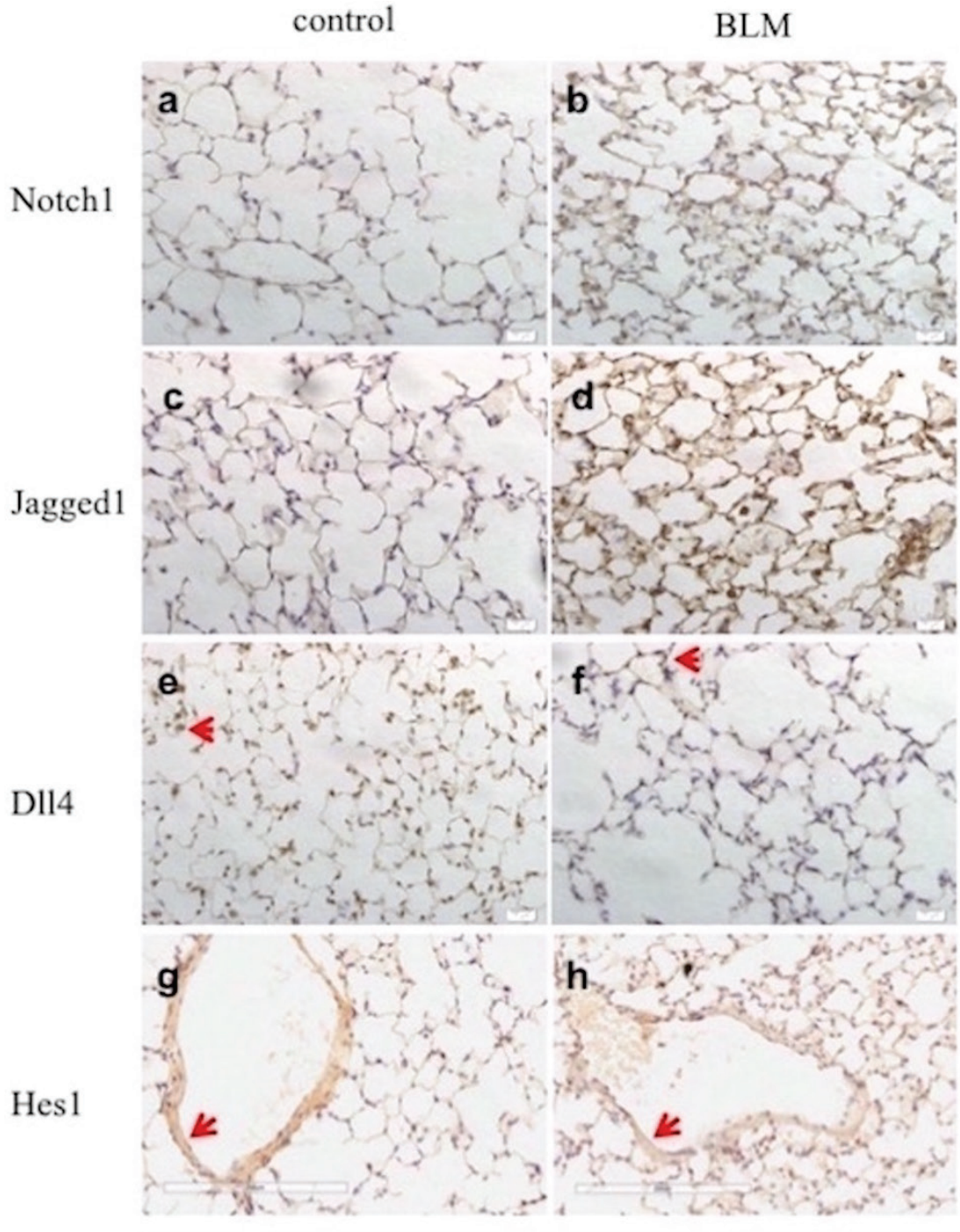

Fig. 3. Immunohistochemistry detection of Notch1, Jagged1, DII4, and Hes1 protein in lung tissue sections. (a) Notch1 staining in the control group. There was little Notch1positive staining in the lung interstitium. (b) Notch1 staining in the BLM group. There was stronger Notch1 positive staining in the lung interstitium, including in the PMVECs. (c) Jagged1 staining in the control group. There was little Jagged1-positive staining in the lung interstitium. (d) Jagged1 staining in the BLM group. There was much stronger Jagged1-positive staining in the thickened lung interstitium. (e) Dll4 staining in the control group, (f) Dll4 staining in the BLM group, (g) Hes1 staining in the control group and (h) Hes1 staining in the BLM group, there was only scant amounts of DII4 and Hes1 positive staining in the lung interstitium of both groups, but more DII4- and Hes1-positive staining was apparent in the microvascular and vascular region of the control lung tissue sections (arrows). (i) Semi-quantitative analysis of the immunohistochemistry staining of Notch1, Jagged1, DII4, and Hes1 proteins in lung tissue sections. The results are presented as the means \pm SD. $* p<0.05$, BLM group vs. control group. Scale bar for Figs $3 a-3 f=20 \mu \mathrm{m}$. Scale bar for Figs $3 \mathrm{~g}$ and $3 \mathrm{~h}=200 \mu \mathrm{m}$.

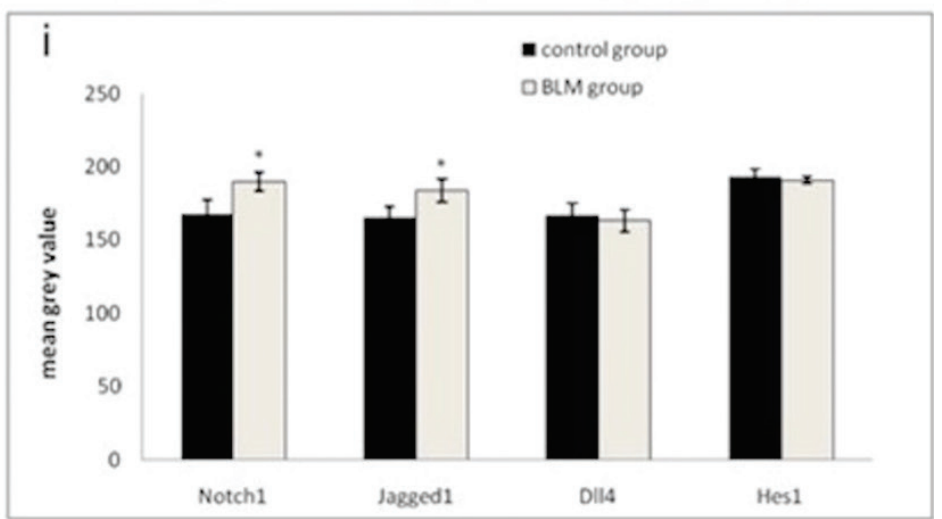

Immunofluorescence analysis of Notch1, Jagged1 and Dll4 protein expression in cultured PMVECs

The immunofluorescence findings from the cultured PMVECs showed that the expression of the Notch signaling receptor Notch1, and one of its ligands, Jagged1, was much higher in the BLM group than in the control group (Figs $4 \mathrm{a}$ and $4 \mathrm{~b}$ ). The differences in mean intensity value were significant (Notch1: $30.77 \pm 3.72$ [BLM] vs. 20.79 \pm 1.44 [control], $p<0.001 ;$ Jagged1: $42.06 \pm 4.81$ [BLM] vs. 24.26 \pm 2.99 [control], $p<0.001$ ) (Fig. 4d). In contrast, the expression of another ligand, Dll4, was significantly lower in the BLM group than in the control group (Fig. 4c) $(23.57 \pm 3.00 \quad$ [BLM] vs. $29.10 \pm 2.25$ [control], $p=0.005$ ) (Fig. 4d). 


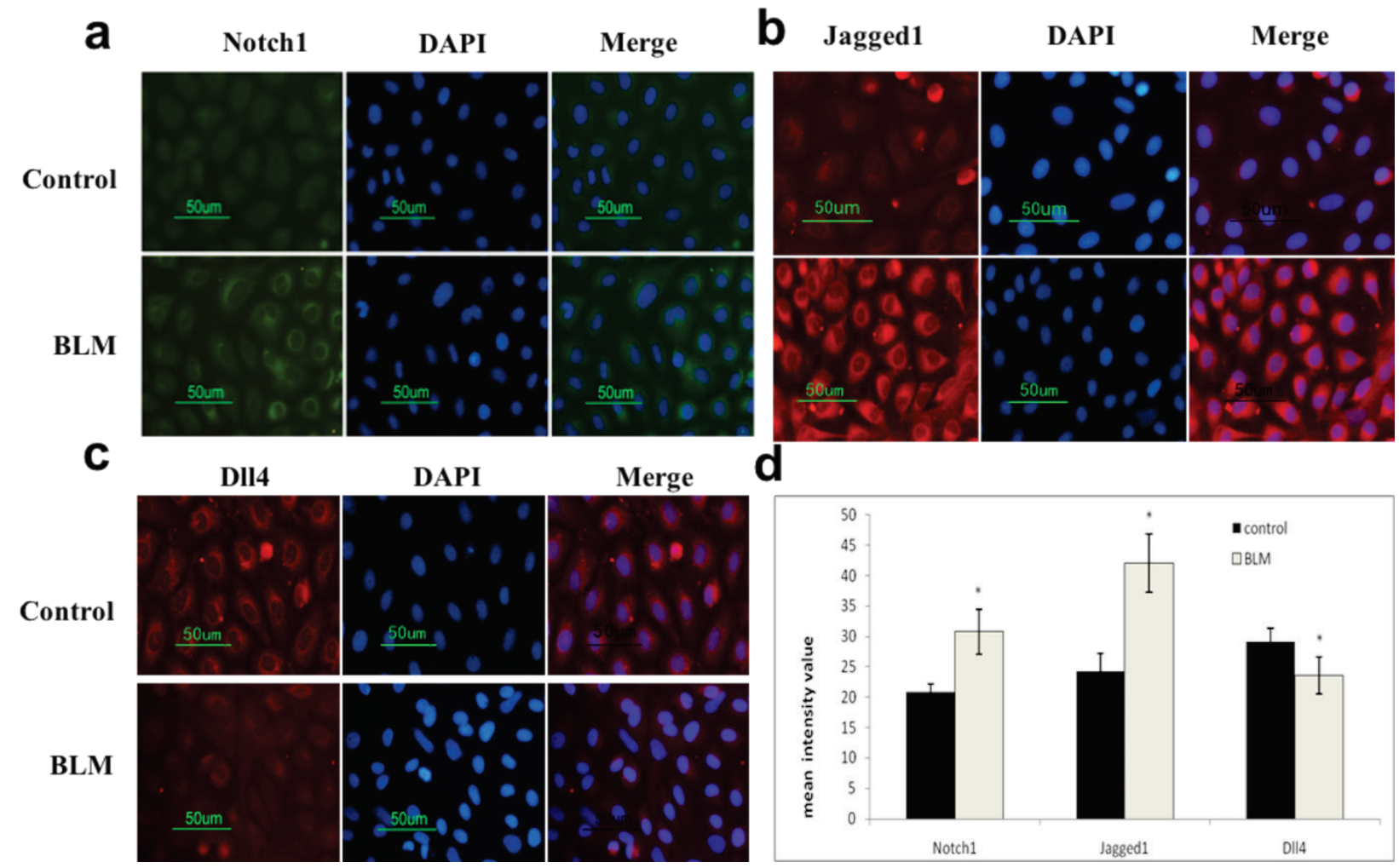

Fig. 4. Immunofluorescence detection of related proteins expression in primary cultured PMVECs. (a) Notch1 immunolabeling was observed predominantly in the cytoplasm and the cell membrane. Notch1 protein immunofluorescence intensity in cultured PMVECs from the BLM group was much higher than that in the control group. (b) Jagged1 immunolabeling was predominantly in the cytoplasm. Jagged1 protein immunofluorescence intensity in cultured PMVECs from the BLM group was much higher than that from the control group. (c) DIl4 immunolabeling was predominantly in the cytoplasm, and slight in the cell membranes. Dll4 protein immunofluorescence intensity observed in cultured PMVECS from the BLM group appeared slightly lower than that from the control group. (d) Semiquantitative analysis of Notch1, Jagged1, and Dll4 protein expression in immunofluorescence cell slides. The results are presented as the means $\pm \mathrm{SD}$. $* p<0.05, \mathrm{BLM}$ group vs. control group. Red: Dll4 protein; blue: DAPI (nuclear stain). Scale bar $=50 \mu \mathrm{m}$.

a

b

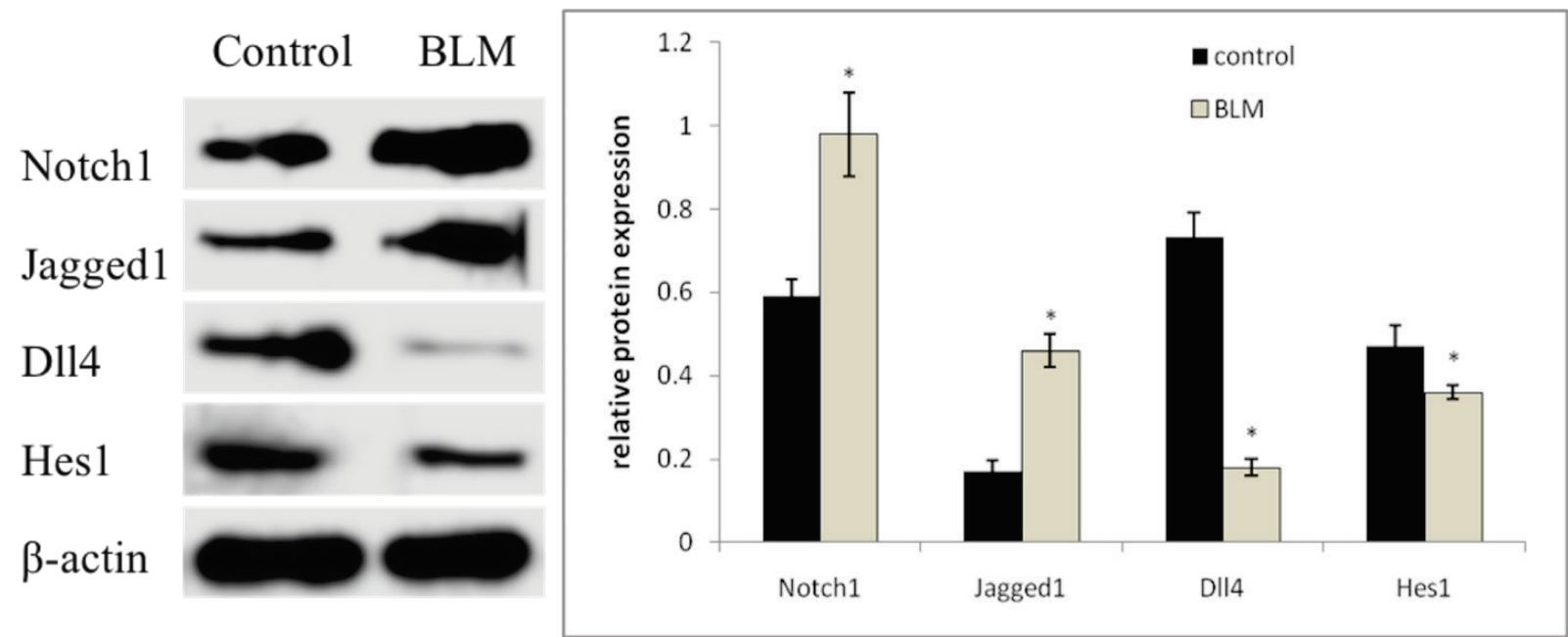

Fig. 5. Western blot detection of related proteins expression in primary cultured PMVECs. (a) Protein bands of Notch1, Jagged1, DII4, and Hes1 in PMVECs. The bands for Notch1 and Jagged1 from the BLM group appear much stronger than that from the control group; however, the bands for DII4 and Hes1 from the BLM group are much fainter than that from the control group. $\beta$-actin was used as the internal control. (b) Analysis of the relative protein band intensities revealing that Notch1 and Jagged1 expression in PMVECs from BLM-treated rats was consistently higher than that in PMVECs from the controls; DIl4 and Hes1 expression in PMVECs from BLM-treated rats was consistently lower than that in PMVECs from the controls. Results are presented as the means \pm SD; $n=3$ independent experiments. ${ }^{*} p<0.05$, BLM group vs. control group. 
Western blot detection of relative expression of Notch1, Jagged1, Dll4, and Hes1 protein in PMVECS

Western blotting confirmed significantly higher Notch1 and Jagged1 protein expression in BLM-treated rat PMVECs than in saline-treated rat PMVECs $(p<0.001)$. However, the expression Dll4 and its target molecule Hes1 in the BLM group was significantly lower than that in the control group $(p<0.001)$ (Fig. 5).

Real-time PCR detection of relative Notch1, Jagged1, Dll4, and Hes 1 mRNA expression in PMVECS

RT-PCR revealed that Notch1 mRNA expression in PMVECs from the BLM group was significantly higher than that from the control group $(p<0.001)$. The expression level of Jagged1 mRNA in PMVECs followed the same trend as that of Notch1 mRNA $(p<0.001)$. Dll4 and Hes1 mRNA expression in PMVECs from the BLM group were significantly lower than that from the control group $(p<0.001)$ (Fig. 6).

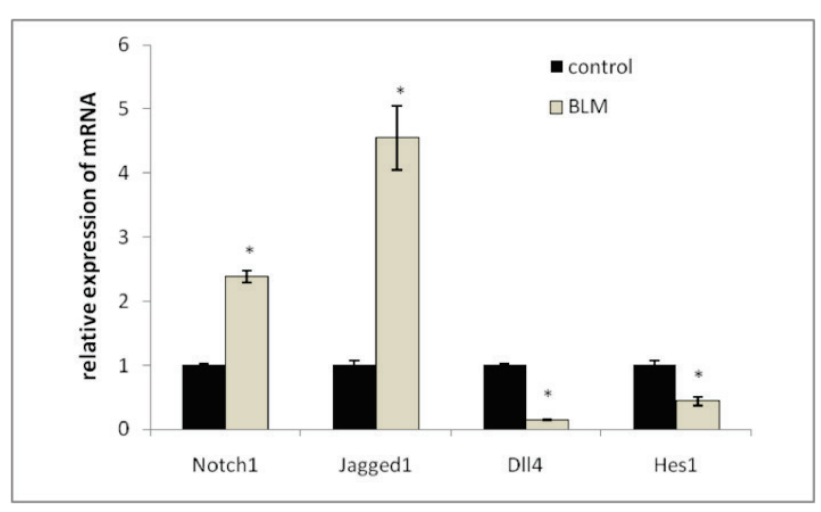

Fig. 6. Real-time PCR detection of relative expression of Notch1, Jagged1, DIl4, and Hes1 mRNA in primary cultured PMVECs. Analysis of the relative mRNA expression reveals that Notch1 and Jagged 1 mRNA expression in PMVECs from BLM-treated rats was higher than that in PMVECs from the controls; DIl4 and Hes1 mRNA expression in PMVECs from BLM-treated rats was lower than that from the controls. Results are presented as the means $\pm \mathrm{SD} ; n=3$ independent experiments. ${ }^{*} p<0.05$, BLM group vs. control group.

\section{Discussion}

The Notch1 signaling pathway, a crucial determinant of cell fate (Artavanis-Tsakonas et al. 1999), regulates cell proliferation, differentiation, migration, and apoptosis (Wang et al. 2007). For ECs in particular, the Notch1 signaling pathway can inhibit the expression of KDR, a vascular endothelial growth factor (VEGF) receptor on ECs, to regulate EC proliferation and differentiation. For example, during angiogenesis, upregulated VEGF can induce higher Dll4 expression on the cell surface, and then Dll4 binds to the Notch1 receptor expressed on adjacent cells; consequently, proteolytic cleavage involving secretase releases NICD, which then translocates into the nucleus, where it binds to its downstream transcription factor CSL. This results in the conversion of CSL from a repressor to an activator with the consequent induction of the transcription of Notch-dependent target genes such as HES1, a transcription inhibitor that downregulates KDR expression. Lastly, this negative feedback loop downregulates the activation of EC proliferation and migration, maintaining EC equilibrium (Holderfield and Hughes 2008). In short, Dll4-induced Notch activation in ECs downregulates EC proliferation, possibly due to attenuated responsiveness to VEGF (Gale et al. 2001).

Clearly, the Notch1 signaling pathway, mediated by Dll4, plays a very important role in inhibiting EC overproliferation, and plays a crucial role in stabilizing vasculature homeostasis. Some experiments have shown that loss of DLL4 function promotes excessive EC sprouting and migration; ECs with DLL4 gene knockdown had high proliferation and migration activity (Benedito et al. 2008). Neutralizing Dll4 expression led to excessive EC proliferation, abnormal differentiation, and cellular dysmaturity (Ridgway et al. 2006, Scehnet et al. 2007). In vivo, inhibiting the Dll4/Notch1 signaling pathway causes uncontrolled vascular sprouting and branch vasculature. These findings confirm that the major role of D1l4 is inhibiting excessive EC proliferation, which is important for maintaining cellular equilibrium. Jagged1 plays the opposite role in the vasculature process. In ECs, upregulation of Jagged1 increases vascular density, promotes vascular development, improves blood perfusion, and accelerates the remodeling of injured tissue (Benedito et al. 2009). Many studies have suggested that Jagged1 inhibits the Dll4/Notch1 signaling pathway by competitively binding to Notch1 on the surfaces of adjacent cells, so it is considered an antagonist of Dll4 (Benedito et al. 2009). Generally, in angiogenesis, Notch1 preferentially binds to Dll4 on adjacent cells (Benedito et al. 2009, Eilken and Adams 2010), playing a role in inhibiting EC overproliferation to regulate the angiogenesis process. However, in some inflammatory circumstances, the transcription of Jagged 1 is markedly upregulated by some cytokines, such as tumor necrosis factor- $\alpha$ (TNF- $\alpha$ ), while Dll4 transcription is downregulated (Benedito et al. 2009, Sainson et al. 2008), which renders the relative 
expression of Jagged1 on the cell surface much higher than that of D114. Consequently, it indirectly inhibits Notch1 binding to D114 and suppresses activation of the Dl14/Notch1 signaling pathway.

Our experiments showed that, in the pathological process of BLM-induced pulmonary fibrosis, Jagged1 expression in PMVECs was upregulated while D114 expression was downregulated. Some reasons for this could be disordered cytokine secretion and the excessive expression of profibrotic cytokines, such as TNF- $\alpha$, which increase the transcription of Jagged 1 and decrease that of Dll4 (Benedito et al. 2009); another reason could be related to the antagonism between Jagged1 and Dll4, meaning Jagged1 upregulation suppresses Dl14 expression (Benedito et al. 2009). Consequently, the decreased expression of Dll4 leads to a decline in the inhibitory regulation of the Dll4/Notch1 signaling pathway suppressing the abnormal overproliferation of PMVECs. This is why PMVECs from BLM-treated rats exhibit disordered proliferation and differentiation (Yin et al. 2011). Meanwhile, the Jagged $1 /$ Notch1 signaling pathway could be related to the presence of $\alpha$-smooth muscle actin ( $\alpha$-SMA) protein in the cytoplasm of PMVECs from BLM-treated rats (Liu et al. 2009). Our experiments also confirmed a positive correlation between the expression of Jagged 1 and $\alpha$-SMA proteins in PMVECs (results not shown). From the above results, we may speculate that the upregulated expression of Jagged1 not only indirectly induces disordered PMVEC proliferation and differentiation, but also directly promotes PMVEC transformation into Endo-MT, which are two important features in the pathological process of BLM-induced rat pulmonary fibrosis.

Our results also reveal that the expression level of Hes1, a downstream target molecule of the canonical Notch signaling pathway, was decreased dramatically in PMVECs from BLM-induced pulmonary fibrosis, which differed from the trends for Jagged1 and Notch1 expression. These results highlight two issues: 1) the lower expression of D114 might inhibit the expression of its downstream target Hes1; 2) Jagged1 and Notch1 combined cannot activate Hes1 expression, which means that the Jagged1/Notch1 signaling pathway could be a so-called non-canonical Notch signaling pathway that does not involve the Hes1-related CBF1 (or RBP-JK) pathway (Dang 2012, Le Gall et al. 2008), and therefore might not affect the normal Notch target genes.

In conclusion, in the early stage of BLM-induced pulmonary fibrosis, excessive secretion of some cytokines promotes increased Jagged1 expression in PMVECs and activates the Jagged1/Notch1 signaling pathway in PMVECs (Benedito et al. 2009, Sainson et al. 2008), which inhibits the role of the Dll4/Notch1 signaling pathway in negative regulation of PMVEC overproliferation, further causing dysfunction in vascular sprouting and maturation; simultaneously, activation of the Jagged1/Notch1 signaling pathway promotes the progress of Endo-MT. These pathological processes all facilitate the development of BLM-induced pulmonary fibrosis. Conversely, Hes1 expression was markedly decreased, indicating that the Jagged1/Notch1 signaling pathway might encourage the progress of BLM-induced pulmonary fibrosis via a non-canonical Notch signaling pathway. The related signal molecules involved in the Jagged1/Notch1 signaling pathway remain to be determined and further elucidated.

\section{Conflict of Interest}

There is no conflict of interest.

\section{Acknowledgements}

We are grateful to Jie Wang for her statistical assistance. We also wish to thank the native English speaking scientists of Elixigen Company (Huntington Beach, California) for editing our manuscript. This work was supported by grants from the National Natural Science Foundation of China (No. 81100043 to Dr. Yin and No. 81200055 to Dr. Wang).

\section{References}

AL HAJ ZEN A, MADEDDU P: Notch signalling in ischaemia-induced angiogenesis. Biochem Soc Trans 37: 1221-1227, 2009.

ARANGUREN XL, LUTTUN A, CLAVEL C, MORENO C, ABIZANDA G, BARAJAS MA, PELACHO B, URIZ M, ARANA M, ECHAVARRI A, SORIANO M, ANDREU EJ, MERINO J, GARCIA-VERDUGO JM, VERFAILLIE CM, PROSPER F: In vitro and in vivo arterial differentiation of human multipotent adult progenitor cells. Blood 109: 2634-2642, 2007. 
ARTAVANIS-TSAKONAS S, RAND MD, LAKE RJ: Notch signaling: cell fate control and signal integration in development. Science 284: 770-776, 1999.

BENEDITO R, TRINDADE A, HIRASHIMA M, HENRIQUE D, DA COSTA LL, ROSSANT J, GILL PS, DUARTE A: Loss of notch signalling induced by Dll4 causes arterial calibre reduction by increasing endothelial cell response to angiogenic stimuli. BMC Dev Biol 8: 117, 2008.

BENEDITO R, ROCA C, SORENSEN I, ADAMS S, GOSSLER A, FRUTTIGER M, ADAMS RH: The notch ligands D114 and Jagged1 have opposing effects on angiogenesis. Cell 137: 1124-1135, 2009.

CALABRESE F, GIACOMETTI C, REA F, LOY M, VALENTE M: Idiopathic interstitial pneumonias: Primum movens: epithelial, endothelial or whatever. Sarcoidosis Vasc Diffuse Lung Dis 22 (Suppl 1): S15-S23, 2005.

CLAXTON S, FRUTTIGER M: Periodic Delta-like 4 expression in developing retinal arteries. Gene Expr Patterns 5: 123-127, 2004.

CLEMENT N, GUEGUEN M, GLORIAN M, BLAISE R, ANDREANI M, BROU C, BAUSERO P, LIMON I: Notch3 and IL-1beta exert opposing effects on a vascular smooth muscle cell inflammatory pathway in which NF-kappaB drives crosstalk. $J$ Cell Sci 120: 3352-3361, 2007.

DANG TP: Notch, apoptosis and cancer. Adv Exp Med Biol 727: 199-209, 2012.

EILKEN HM, ADAMS RH: Dynamics of endothelial cell behavior in sprouting angiogenesis. Curr Opin Cell Biol 22: 617-625, 2010.

GALE NW, BALUK P, PAN L, KWAN M, HOLASH J, DECHIARA TM, MCDONALD DM, YANCOPOULOS GD: Ephrin-B2 selectively marks arterial vessels and neovascularization sites in the adult, with expression in both endothelial and smooth-muscle cells. Dev Biol 230: 151-160, 2001.

HOLDERFIELD MT, HUGHES CC: Crosstalk between vascular endothelial growth factor, notch, and transforming growth factor-beta in vascular morphogenesis. Circ Res 102: 637-652, 2008.

JEGAL Y, KIM DS, SHIM TS, LIM CM, DO LEE S, KOH Y, KIM WS, KIM WD, LEE JS, TRAVIS WD, KITAICHI M, COLBY TV: Physiology is a stronger predictor of survival than pathology in fibrotic interstitial pneumonia. Am J Respir Crit Care Med 171: 639-644, 2005.

JURYNCZYK M, JUREWICZ A, BIELECKI B, RAINE CS, SELMAJ K: Inhibition of notch signaling enhances tissue repair in an animal model of multiple sclerosis. J Neuroimmunol 170: 3-10, 2005.

KASPER M, SEIDEL D, KNELS L, MORISHIMA N, NEISSER A, BRAMKE S, KOSLOWSKI R: Early signs of lung fibrosis after in vitro treatment of rat lung slices with $\mathrm{CdCl} 2$ and TGF-beta1. Histochem Cell Biol 121: 131-140, 2004.

KUME T: Ligand-dependent notch signaling in vascular formation. Adv Exp Med Biol 727: 210-222, 2012.

KURUVILLA L, KARTHA CC: Treatment with TNF-alpha or bacterial lipopolysaccharide attenuates endocardial endothelial cell-mediated stimulation of cardiac fibroblasts. J Biomed Sci 16: 21, 2009.

KWON SM, ALEV C, LEE SH, ASAHARA T: The molecular basis of notch signaling: a brief overview. Adv Exp Med Biol 727: 1-14, 2012.

LANG C, SAUTER M, SZALAY G, RACCHI G, GRASSI G, RAINALDI G, MERCATANTI A, LANG F, KANDOLF R, KLINGEL K: Connective tissue growth factor: A crucial cytokine-mediating cardiac fibrosis in ongoing enterovirus myocarditis. J Mol Med (Berl) 86: 49-60, 2008.

LE GALL M, De MATTEI C, GINIGER E: Molecular separation of two signaling pathways for the receptor, Notch. Dev Biol 313: 556-567, 2008.

LIU T, HU B, CHOI YY, CHUNG M, ULLENBRUCH M, YU H, LOWE JB, PHAN SH: Notch1 signaling in FIZZ1 induction of myofibroblast differentiation. Am J Pathol 174: 1745-1755, 2009.

MAURO M, KIM J, COSTELLO C, LAURENCE J: Role of transforming growth factor beta1 in microvascular endothelial cell apoptosis associated with thrombotic thrombocytopenic purpura and hemolytic-uremic syndrome. Am J Hematol 66: 12-22, 2001.

MUEHLICH S, CICHA I, GARLICHS CD, KRUEGER B, POSERN G, GOPPELT-STRUEBE M: Actin-dependent regulation of connective tissue growth factor. Am J Physiol Cell Physiol 292: C1732-C1738, 2007.

MUTSAERS SE, FOSTER ML, CHAMBERS RC, LAURENT GJ, MCANULTY RJ: Increased endothelin-1 and its localization during the development of bleomycin-induced pulmonary fibrosis in rats. Am J Respir Cell Mol Biol 18: 611-619, 1998. 
PHAN SH, GHARAEE-KERMANI M, WOLBER F, RYAN US: Stimulation of rat endothelial cell transforming growth factor-beta production by bleomycin. J Clin Invest 87: 148-154, 1991.

RIDGWAY J, ZHANG G, WU Y, STAWICKI S, LIANG WC, CHANTHERY Y, KOWALSKI J, WATTS RJ, CALLAHAN C, KASMAN I, SINGH M, CHIEN M, TAN C, HONGO JA, DE SAUVAGE F, PLOWMAN G, YAN M: Inhibition of Dll4 signalling inhibits tumour growth by deregulating angiogenesis. Nature 444: 1083-1087, 2006.

SAINSON RC, JOHNSTON DA, CHU HC, HOLDERFIELD MT, NAKATSU MN, CRAMPTON SP, DAVIS J, CONN E, HUGHES CC: TNF primes endothelial cells for angiogenic sprouting by inducing a tip cell phenotype. Blood 111: 4997-5007, 2008.

SAKAO S, TARASEVICIENE-STEWART L, WOOD K, COOL CD, VOELKEL NF: Apoptosis of pulmonary microvascular endothelial cells stimulates vascular smooth muscle cell growth. Am J Physiol Lung Cell Mol Physiol 291: L362-L368, 2006.

SCEHNET JS, JIANG W, KUMAR SR, KRASNOPEROV V, TRINDADE A, BENEDITO R, DJOKOVIC D, BORGES C, LEY EJ, DUARTE A, GILL PS: Inhibition of Dll4-mediated signaling induces proliferation of immature vessels and results in poor tissue perfusion. Blood 109: 4753-4760, 2007.

TAKABATAKE N, ARAO T, SATA M, ABE S, INOUE S, SHIBATA Y, TAKEISHI Y, KUBOTA I: Involvement of pulmonary endothelial cell injury in the pathogenesis of pulmonary fibrosis: clinical assessment by 123 I-MIBG lung scintigraphy. Eur J Nucl Med Mol Imaging 32: 221-228, 2005.

TU L, FANG TC, ARTIS D, SHESTOVA O, PROSS SE, MAILLARD I, PEAR WS: Notch signaling is an important regulator of type 2 immunity. J Exp Med 202: 1037-1042, 2005.

WANG Z, KONG D, BANERJEE S, LI Y, ADSAY NV, ABBRUZZESE J, SARKAR FH: Down-regulation of platelet-derived growth factor-D inhibits cell growth and angiogenesis through inactivation of Notch-1 and nuclear factor-kappaB signaling. Cancer Res 67: 11377-11385, 2007.

YIN Q, NAN HY, ZHANG WH, YAN LF, CUI GB, HUANG XF, WEI JG: Pulmonary microvascular endothelial cells from bleomycin-induced rats promote the transformation and collagen synthesis of fibroblasts. $J$ Cell Physiol 226: 2091-2102, 2011.

YIN Q, NAN H, YAN L, HUANG X, WANG W, CUI G, WEI J: Alteration of tight junctions in pulmonary microvascular endothelial cells in bleomycin-treated rats. Exp Toxicol Pathol 64: 81-91, 2012. 